\title{
Endoscopic Endonasal Odontoidectomy
}

\author{
Krishna Joshi ${ }^{1}$ Troy Woodard ${ }^{2}$ Hamid Borghei-Razavi ${ }^{1}$ Pablo F. Recinos ${ }^{1}$ Varun R. Kshettry ${ }^{2}$
}

${ }^{1}$ Department of Neurosurgery, Rose Ella Burkhardt Brain Tumor \& Neuro-Oncology Center, Neurological Institute, Cleveland Clinic, Cleveland, Ohio, United States

2 Department of Otolaryngology, Head \& Neck Institute, Cleveland Clinic, Cleveland, Ohio, United States
Address for correspondence Varun Kshettry, MD, Cleveland Clinic, 9500 Euclid Avenue, CA5-86, Cleveland, OH 44195, United States (e-mail: kshettv@ccf.org).

J Neurol Surg B 2019;80(suppl S4):S370.

\begin{abstract}
Keywords

- endoscopy

- odontoidectomy

- craniovertebral junction

- endonasal

Odontoidectomy is a standard procedure employed in the treatment of irreducible, compressive ventral pathologies of the craniovertebral junction (CVJ). The traditionally used transoral route is often challenging due to the increased depth of the surgical corridor and risk of injuries to the soft tissues in the oral cavity. The emergence of endoscopic endonasal (EE) surgery has provided an attractive alternative route to the traditional treatment algorithm, and it has the advantages of avoiding complications related to tongue swelling, tracheal swelling, prolonged intubation, velopharyngeal insufficiency, dysphagia, and dysphonia.

We present a case of a 66-year-old man with no pertinent past medical history, who presented with progressive quadriparesis and gait ataxia over last 6 months (Nurick's grade 2). Neurological exam revealed pattern suggestive of high-cervical myelopathy with no evidence of cranial nerve paresis. Magnetic resonance imaging (MRI) of his CV] revealed a large pannus behind the dens with severe spinal cord compression, mild contrast enhancement was noted posterior to the pannus, likely from the ligamentous structures; pannus was hypointense on both T1- and T2-weighted images. Further, a computerized tomography (CT) scan did not reveal any obvious malalignment. He underwent an EE odontoidectomy, followed by posterior cervical fusion. He had an unremarkable postoperative period and recovered fully from his myelopathy over the next 6 months. The histopathological examination of the pannus revealed a degenerated disk. In this video, we have a step by step description of the EE approach to the odontoid and discuss the surgical nuances.

The link to the video can be found at: https://youtu.be/pjg68_vK0C4.
\end{abstract}

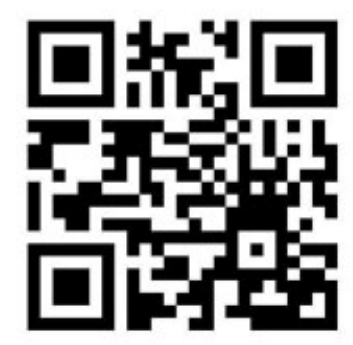

received

April 1, 2019

accepted

August 25, 2019

published online

October 23, 2019

Conflict of Interest

None declared.

www.thieme.com/skullbasevideos

www.thieme.com/jnlsbvideos

DOI https://doi.org/

10.1055/s-0039-1700510.

ISSN 2193-6331. (c) 2019 Georg Thieme Verlag KG

Stuttgart · New York
License terms

(c) (i) $\ominus$ (요 